\title{
A framework for teaching socio-environmental problem-solving
}

\section{Cynthia A. Wei ${ }^{1,2}$ (D) Michael L. Deaton $^{3} \cdot$ Teresa J. Shume $^{4}$ (D) Ramiro Berardo $^{5} \cdot$ William R. Burnside $^{1}$ (D)}

Published online: 11 April 2020

(C) The Author(s) 2020, corrected publication 2020

\begin{abstract}
The urgent environmental challenges we now face, from climate change to biodiversity loss, involve people and the planet, the social, and the environmental. Teaching students to become effective socio-environmental problem-solvers requires clarity about concepts and competencies needed to understand and tackle these challenges. Here, we propose an educational framework that describes what students should learn and how they should apply this knowledge to address socio-environmental problems. This framework emphasizes the process of problem-solving and is based on socio-environmental (S-E) synthesis, an integrative, transdisciplinary approach to understanding and tackling complex socio-environmental problems. In addition to identifying the knowledge, skills, dispositions, and practices necessary for S-E problem-solving at the undergraduate and graduate levels, we clarify how one draws on such competencies to inquire about problems and generate solutions for them. Our primary goal is to provide a useful tool to help guide development of curricula, teaching materials, and pedagogies for S-E synthesis and interdisciplinary environmental education more broadly.
\end{abstract}

Keywords Systems $\cdot$ Complexity $\cdot$ Socio-environmental $\cdot$ Synthesis $\cdot$ Interdisciplinary $\cdot$ Education $\cdot$ Framework $\cdot$ Competencies

\section{Introduction}

Preparing students to understand and address complex and often global environmental problems is a critical and growing challenge for higher education. These problems, such as transboundary pollution, overfishing, and biodiversity loss, confound teams of seasoned experts and entire societies. Not surprisingly, interdisciplinary environmental and sustainability (IES) programs, whose common goal is to train students to become "sustainability-oriented scientists, leaders, problem

The original version of this article was revised due to a retrospective Open Access order

\section{Cynthia A. Wei \\ Cynthia.Wei@georgetown.edu}

1 National Socio-Environmental Synthesis Center (SESYNC), 1 Park Place Suite 300, Annapolis, MD 21401, USA

2 Walsh School of Foreign Service, Georgetown University, 3700 O St. NW, Washington DC 20057, USA

3 School of Integrated Sciences, James Madison University, MSC 4102, 701 Carrier Drive, Harrisonburg, VA 22807, USA

4 School of Education, North Dakota State University, Dept. 2625, PO Box 6050, Fargo, ND 58108, USA

5 School of Environment and Natural Resources, The Ohio State University, 316B Kottman Hall, Columbus, OH 43210, USA solvers, and decision makers" (Vincent and Focht 2010), have struggled to articulate coherent and effective ways to meet this challenge (Vincent and Focht 2010; Clark et al. 2011). This difficulty lies, in part, in the complex, interdisciplinary, and often contested nature of most environmental and sustainability issues. Such problems are often described as socio-environmental (S-E) in recognition of the intertwined nature of their natural and social dimensions. Given the interdisciplinary nature of S-E problems, developing solutions usually require integrating insights from the natural and social sciences, engineering, and other fields (NAS 2005; Turner II et al. 2016). Such integration is itself challenging because epistemological differences, including the discussion of what constitutes valid knowledge and evidence, can be substantial (Eigenbrode et al. 2007). Furthermore, the societal context of S-E problems, along with the need to develop solutions that are embraced by stakeholders with often competing agendas, necessitates a transdisciplinary approach (Mobjörk 2010), transcending disciplinary boundaries and engaging perspectives and actors beyond academia. Transdisciplinary work requires individual and team competencies that can be complicated and difficult to articulate. Yet, a clear understanding of how such work is done and the needed competencies associated with it are necessary prerequisites to prepare students to be effective S-E researchers and problem-solvers.

In this paper, our goal is to provide a generalized description of the process of S-E problem-solving and the competencies required for this. We describe them as part of an integrated 
problem-solving framework to guide pedagogical and curriculum development, which we hope can be of use to the many disciplines and traditions engaged in S-E problem-solving, from natural resources management to sustainability science. This framework leverages $S-E$ synthesis, an integrative, transdisciplinary approach to studying and addressing S-E problems (Turner II et al. 2016; Palmer et al. 2016; Palmer 2012).

Although the skills and knowledge researchers and practitioners employ in S-E synthesis are broad and varied, our framework incorporates three core ideas. First, S-E synthesis is fundamentally system oriented, focusing on the human-nature interface and the holistic perspective advocated by interdisciplinary environmental (IE) program leaders, (Vincent and Focht 2011). Practitioners of S-E synthesis assume that environmental problems emerge from an underlying system and that how that system "works" is the key to understanding how these problems form and persist over time (e.g., Meadows 2008). Second, S-E synthesis involves integrating existing knowledge, data, and methods across disciplinary boundaries to advance understanding of S-E systems (Pennington et al. 2016). For example, researchers have used novel computational methods to combine data on industrial toxic pollution with socio-demographic data to empirically study societal power dynamics in relation to environmental degradation (Collins et al. 2016). Third, S-E synthesis emphasizes the production of knowledge that can inform decision-making or "actionable science," and thus favors transdisciplinary research (as defined in Mobjörk 2010) that engages participants beyond academia in codefining research questions and desired end products (Palmer 2012; Lynch et al. 2015). While the core ideas that comprise the approach are not new, we focus on S-E synthesis in building an educational framework, because our main goal is to provide a critical perspective for designing curricula to prepare students to effectively implement S-E problem-solving.

S-E synthesis provides a powerful foundation for an education framework because it offers several benefits: First, the integrated study of social and environmental systems provides a more holistic picture of the complexity that underlies socio-environmental problems and systems than would be apparent through social or natural science studies alone (Liu et al. 2007). Second, the use of existing data, methods, and ideas in synthesis research facilitates the development of new approaches and expands opportunities for novel analyses (Carpenter et al. 2009). Third, by bringing together people and disciplines usually distinct, it has the potential to promote unforeseen insights and collaborations and to inform practical solutions (Lynch et al. 2015). Like systems themselves, it can catalyze emergent outcomes.

\section{The need for a unified educational framework for S-E problem-solving}

Many fields have focused on identifying core competencies students should develop (biology: AAAS 2011; physics:
AAPT 2014) as prerequisites to developing disciplinary identity and as guidance for the development of programs, curricula, and classroom materials. In the environment and sustainability fields, there have also been many efforts to articulate requisite competencies (reviewed in Wiek et al. 2011, Lozano et al. 2017, Sterling et al. 2017, and Evans 2019). These efforts share the common trait of emphasizing competencies that prepare students to work with complex systems (e.g., Frisk and Larson 2011). Yet, few of these efforts have provided a coherent picture of what students should learn, instead offering bulleted lists of competencies to learn (as noted by Wiek et al. 2011). In contrast to disciplinary training, where there is relatively good agreement on foundational theories, concepts, and skills, the arena of IES education lacks such clarity (Vincent and Focht 2011, but see Wiek et al. 2011 and Segalas et al. 2009). Within IES programs, students “... see their basic educational task as acquiring disciplinary knowledge and skills ... They trust that a mix of these disciplines and methods will provide them with a sufficient tool kit" (Clark and Wallace 2015, p. 248). However, such an approach is insufficient: What is also needed is guidance on how and when to apply and integrate the knowledge and skills in their "toolkit"; a framework can help provide and visualize that guidance (Clark and Wallace 2015; Wiek et al. 2011).

\section{Toward a unified educational framework for S-E problem-solving}

Here, we propose an educational framework that summarizes and articulates the knowledge, skills, dispositions, and practices necessary for undergraduate and graduate students to engage in socio-environmental research and problem-solving. It explains the relationships among these elements to help clarify how one approaches problems, conducts inquiry, and generates solutions. We hope that it will serve as a coherent vision that avoids the problems identified by Clark et al. (2011) and others for IES programs. At the undergraduate level, we hope that it provides both guidance on the foundational competencies students should be developing and a clearer understanding of why these competencies are critical to learn. Moreover, we hope that the framework provides inspiration for the design of pedagogical approaches, such as problem-based learning or case study methods that enable students to practice these competencies to assess and solve socio-environmental problems. At the graduate level, this framework can guide the development of opportunities for more-advanced practice and integration of competencies in the context of socio-environmental problem-solving.

The genesis of this framework began in a workshop on Teaching about Socio-Environmental Synthesis: Moving Towards Best Practices convened at the National SocioEnvironmental Synthesis Center (SESYNC) on June 21-24, 
2016.. Participants represented a broad range of disciplinary expertise (ecology, evolutionary biology, sustainability, anthropology, philosophy, education, systems science, policy, and environmental science) and experience in S-E synthesis research and had developed S-E synthesis case studies that had been used in the classroom. During the workshop, this group sought to identify the full set of competencies and practices needed for students to undertake S-E synthesis research and problem-solving and ultimately identified four competency domains: systems thinking, boundary crossing, sociocultural awareness, and integrative research. These domains, described below, collectively encompass the diverse skills and practices involved in S-E synthesis and provide guidance for developing student-focused learning outcomes for S-E synthesis.

However, taken in isolation, the four competency domains do not provide sufficient guidance for how to use these competencies in the process of actually doing S-E synthesis work. They can quickly be treated as another more highly aggregated bullet list of skills and knowledge. They need to be placed within a problemsolving framework in order to promote the interdisciplinary integration practices that characterize S-E problem-solving. Drawing on Ostrom (2009), such a framework should provide (a) a broad goal-oriented process of inquiry and problem-solving within which individual competencies are applied, (b) a holistic approach for gathering and creating synthesized knowledge across multiple domains (Clark and Wallace 2015), and (c) clear connections between individual competencies and the greater S-E problem-solving effort.

Recognizing the need for these criteria, the authors of this paper, who comprise a subset of the original workshop participants, continued discussions following the workshop to develop a framework emphasizing the process of socioenvironmental problem-solving and the role of various competencies in that process. These conversations and the related literature selection process built on our collective experiences as educators, researchers, and practitioners in the environmental arena and our expertise in socio-environmental synthesis, systems science, sustainability science, policy, and environmental education and pedagogy.

The framework we have developed contains four components, all of which should be addressed when designing educational experiences aimed at developing these skills: 1) the desired outcomes from S-E synthesis, 2) the process of inquiry for achieving them, 3) the competencies required, and 4) the interrelationships between all of these. These building blocks and their relationships are shown in Figs. 1, 2, and 3 and described in detail in the accompanying discussion below.

\section{The desired outcomes from S-E synthesis}

Beginning with the end in mind, Fig. 1 shows five outcomes of S-E synthesis and problem-solving (Fig. 1). The outcomes we suggest are insights that reflect and therefore mirror characteristics of S-E challenges. For example, to tackle a challenge in its systemic reality, one must understand the system's role in the problem. Comparable to Marzano's (2009) learning goals that encompass both declarative (i.e., what) and procedural (i.e., how to) knowledge, one can think of these outcomes as being the kinds of insights or knowledge that should be the result of any S-E synthesis effort. We briefly describe these outcomes and illustrate them with a case study of the rock lobster fishery in Western Australia.

In the early twentieth century, commercial fishing operations in the Western Australian rock lobster fishery reaped a bountiful harvest of lobster and correspondingly bountiful economic return. This stimulated further growth of commercial fishing and an even greater total harvest - a self-reinforcing cycle of growth. Following WWII, the annual harvest grew from less than 500 metric tons to over 8000 metric tons in the 1950s. Moreover, this growth brought with it more sophisticated and efficient fishing technologies that enabled fishing fleets to continue reaping a profitable harvest. This effectively masked the decline in the lobster population, and by the mid-twentieth century when the lobster population had reached critically low levels, it was almost too late to take action (Phillips et al. 2007). We consider the implications below.

\section{Outcome \#1: identification of the system actors, dynamics, and boundaries}

S-E problems emerge and are sustained by systems involving interactions among both human (social) and natural (biophysical) actors and forces. Understanding S-E problems and finding sustainable solutions require an analysis of the structures, boundaries, and behavior of those systems. Doing so minimizes the potential for misinformed or naïve analyses that fail to account for factors that are geographically or temporally distant from the obvious symptoms of the problem. In addition, this allows stakeholders to see their own goals and actions in light of their broader impact. For example, in the case of the western rock lobster fishery, overexploitation was a natural outcome created by interactions between economic forces, natural ecosystem dynamics, lobster fishermen, and consumers. Sustainable solutions for such a problem require that analyses consider the roles of those actors, economic realities, and the ecosystem.

\section{Outcome \#2: illuminating the role of the system in the problem}

Once the scope and boundaries of the underlying system(s) are identified, an analysis of system structure will lead to insights about how certain characteristics of the system may actually contribute to creating the problem and making it resistant to change. Learning how to identify and evaluate the 
Fig. 1 This figure identifies the five desired outcomes of a S-E synthesis problem-solving process that lead to sustainable solutions. The goals are described as enhanced insights toward each of the five outcomes identified by the dashed arrows

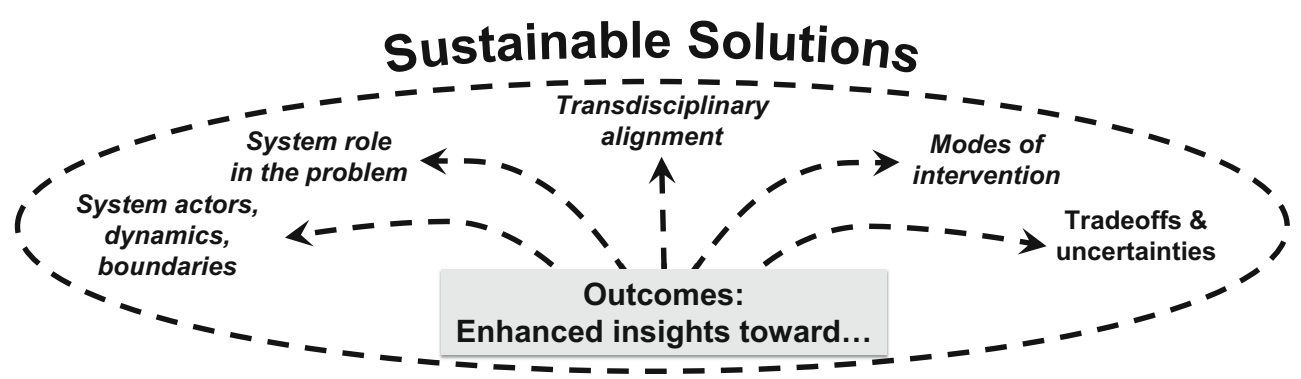

roles of structural features such as feedback dynamics, delays from cause to effect, emergent behavior, and sources of momentum is critical.

In the rock lobster example, the near collapse of the fishery was not the intent or goal of the actors in the system. It was instead an emergent outcome - created by the feedback dynamics and information delays in the system. By accounting for the role of these system features and by finding ways to subvert them, managers eventually identified and implemented viable interventions.

\section{Outcome \#3: transdisciplinary alignment toward shared understanding of problem}

Progress toward a sustainable solution is not possible unless relevant decision-makers and stakeholders reach a common understanding of the roots of the problemhow the interactions of the actors (human and otherwise) collectively contribute to the problem. Achieving such transdisciplinary alignment requires close collaboration between disciplinary experts, stakeholders, and decisionmakers-each bringing critical knowledge from distinct and complementary vantage points. Without consistent effort to facilitate this collaboration, the entire endeavor can regress into a conflict-ridden state in which scientific, social, and political realities clash. A shared understanding of the problem will be impossible, and progress toward sustainable solutions will be unlikely.

In 1965, in response to the developing crisis in the Western Australian rock lobster fishery, the Australian government passed the Fish Resources Management Act, which created the Rock Lobster Industry Advisory Committee, comprised of fishery researchers, fishermen, and fishery managers from the Australian government. This group was charged with developing an approach that would enable a sustainable, economically profitable, and ecologically sound western rock lobster fishery. The diverse makeup of this transdisciplinary group enabled a holistic analysis of the problem that drew on the critical expertise of stakeholders, scientists, and policymakers. This body continues to operate today.
Fig. 2 The circular schematic at the bottom of this figure illustrates the key components of the S-E synthesis process of inquiry that leads to the desired outcomes described at the top (and in Fig. 1). Arrows indicate the directionality of the process and highlight the point that the process is iterative and can be entered at any point

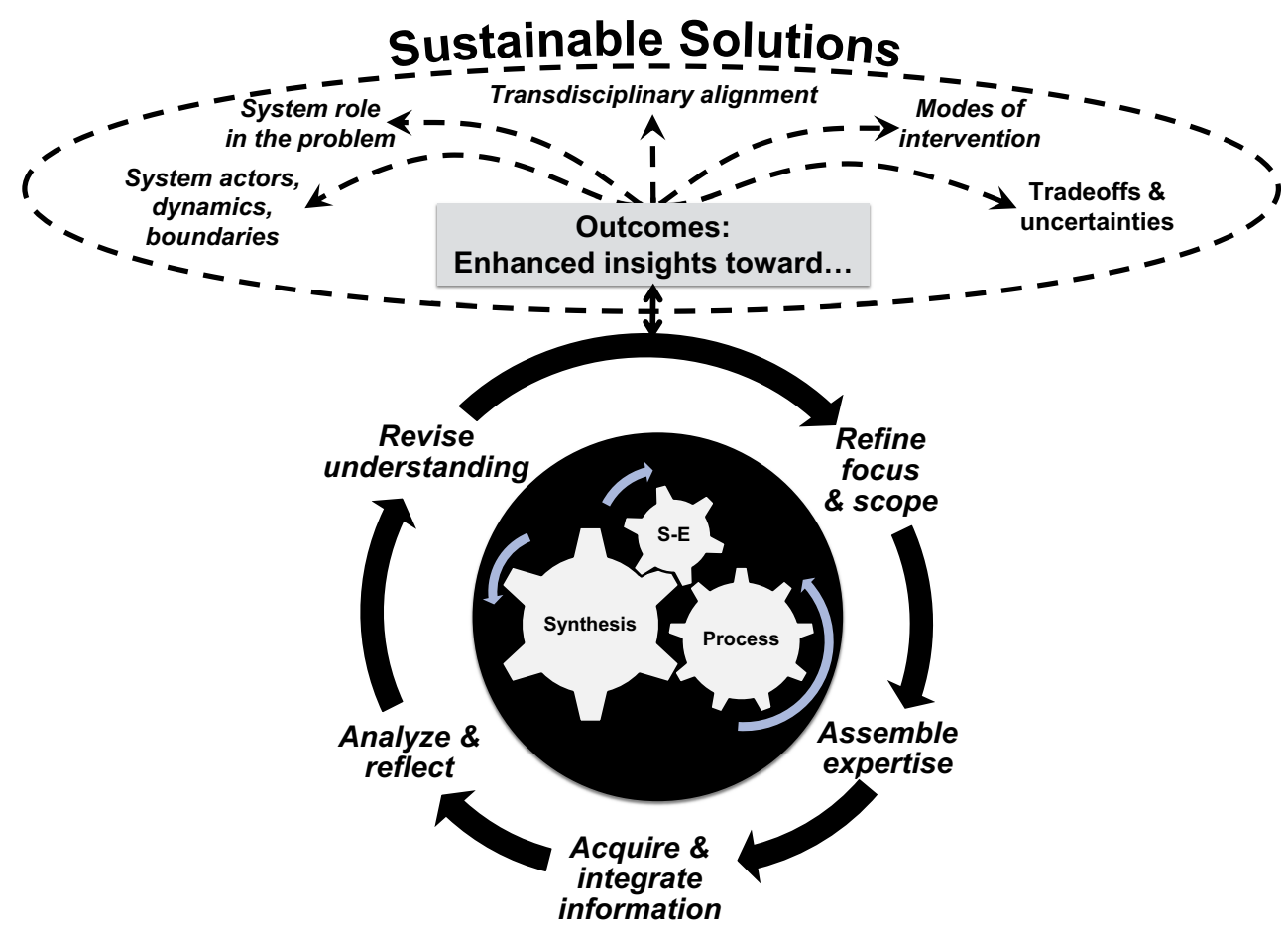


Fig. 3 This figure illustrates complete framework by adding the four competency domains. The four large arrows indicate that each competency domain is used throughout the S-E synthesis process

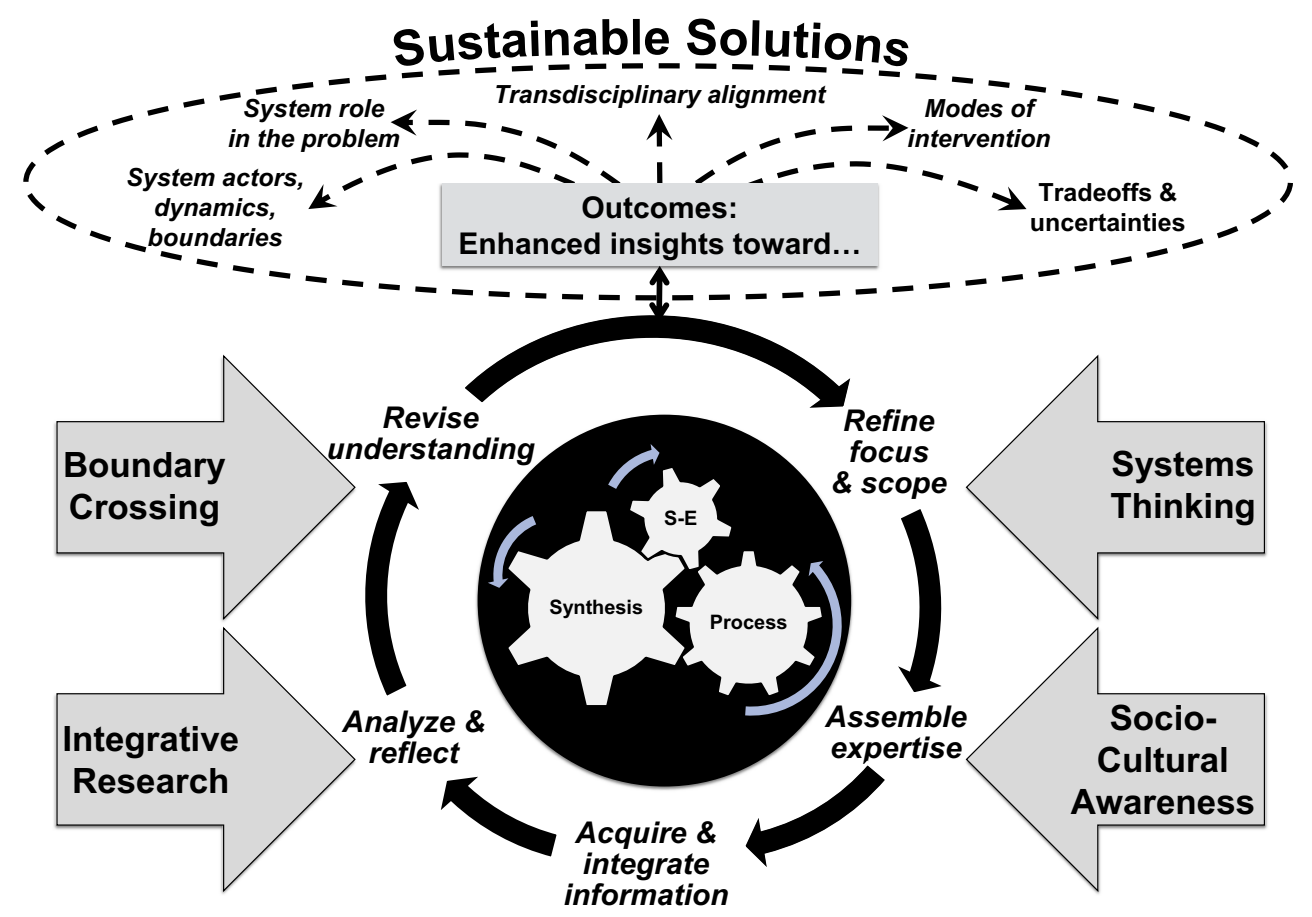

\section{Outcome \#4: identification of effective modes of intervention}

Given a common understanding of the systemic roots of the problem, the S-E synthesis effort should identify options for effectively and ethically intervening to solve the problem. Rather than simplistic prescriptions based on naïve causeeffect explanations or unfounded sociocultural assumptions, these interventions are instead informed by the transdisciplinary, system-level understanding of the problem, corresponding to the other outcomes.

The efforts of the Rock Lobster Industry Advisory Committee eventually led to a series of principles that have guided the management of the fishery since at least the 1970s (Phillips et al. 2007). These principles exemplify an approach that is founded on solid science and that value the input and considerations of the commercial fishing industry and have proven to be a highly successful guide since their adoption. In the past two decades, the western rock lobster fishery has consistently been recognized as one of the best managed fisheries in the world (Phillips et al. 2007).

\section{Outcome \#5: identification of tradeoffs and uncertainties associated with proposed interventions}

S-E problems are characterized by tradeoffs between competing goals among stakeholders and often between what stakeholders require to pursue their own goals and what is required for the long-term sustainability of natural resources.
Moreover, the nature and intensity of these tradeoffs are often not clear, and many of the factors involved are not easily measured. In addition, because S-E systems adapt to change, any intervention can lead to unintended consequences (Sterman 2000). Hence, an S-E synthesis effort should explore these tradeoffs and uncertainties by identifying and evaluating assumptions that could have a significant bearing on the veracity of the analysis.

For example, the principles guiding management of the western rock lobster fishery require an annual reevaluation of the size of the fishing fleet and allowable harvest. This is informed by ongoing research, monitoring of environmental conditions, and predictions of fishery recruitment rates. These policies inevitably impose short-term hardships on those whose livelihoods depend on the annual harvest, and have fueled illegal fishing activity. Through the cooperative efforts of the members of the Rock Lobster Industry Advisory Committee, adaptive inspection and enforcement activities have proven highly effective in combating such illegal activity.

\section{The process of inquiry for achieving these outcomes}

How are these outcomes achieved? The process by which S-E synthesis leads to them is described in Fig. 2 and draws from Burnside et al. (2015 presentation at the Association for Environmental Studies and Sciences) and Palmer (2017), who describe the phases of S-E synthesis research, as well 
as Bammer (2013) and Clark and Wallace (2015), who describe the kinds of activities involved in interdisciplinary or transdisciplinary work. The order in which the process activities are presented should be interpreted as a logical ordering, but not as a rigid step-wise procedure. In fact, many of these activities are concurrent and recursive; findings from one activity might lead to a revisiting of work done in earlier stages.

\section{Process activity \#1: refine focus and scope}

One of the great challenges in S-E problem-solving is clarifying both the problem and the goals of the analysis. The variety of actors involved; their complex interactions with their natural setting; and the potentially broad temporal, governance, and geographic scales of the problem can readily lead to an amorphous set of responses devoid of much-needed consistency. Thus, an important part of the S-E problem-solving process is the refinement of the research questions in response to new insights gained. As new knowledge is gained or as collaborators provide different perspectives, the focus, scope, and desired outcomes of the research may evolve over time.

\section{Process activity \#2: assemble expertise}

A key task is to identify and assemble the expertise and knowledge required to address a given S-E problem, and the required expertise depends on the focus and scope of the problem and the desired outcomes of the effort. The nature of S-E problems typically necessitates the inclusion of diverse disciplinary expertise, as well as contextual, "on the ground" expertise of decision-makers and stakeholders. When possible, the team makeup should be fluid, evolving as the project progresses and incorporating needed expertise as the nature of problems evolves.

\section{Process activity \#3: acquire and integrate information}

Given the diversity in expertise and knowledge required to address a particular S-E problem, the types of information that must be considered are similarly diverse and heterogeneous. A hallmark of S-E synthesis is the integration of disparate data and knowledge, which is a significant challenge because data may be of differing types (quantitative and qualitative), may span differing spatial and temporal scales, may be located across many sources, or may not exist in the format necessary for analysis. Additionally, this important phase of the S-E synthesis process often requires a recognition and accommodation of differing views of what constitutes reliable data and valid evidence.

\section{Process activity \#4: analyze and reflect}

An important part of the S-E synthesis process is identifying or developing appropriate analytical methods and implementing them to draw meaningful conclusions; this often requires sophisticated data analytic methods (Palmer 2017). It is also important to continually reflect on how the results of analysis support or contradict the prevailing understanding of the likely causes - and consequences - of a given problem. This activity involves metacognitive processes through which assumptions are checked, mental models evaluated and revised, and sociocultural biases identified and addressed.

\section{Process activity \#5: revise current understanding}

Throughout the process, the current understanding of both the nature and extent of the problem as well as its systemic causes is continually updated as insights emerge and hypotheses are formed and tested. This in turn can lead to a further refinement of the project scope and focus, and so on, as indicated in the circular nature of the process.

\section{Competencies for S-E synthesis}

The foregoing discussion implies that successful S-E synthesis efforts depend on the proficient application of a sophisticated and integrated portfolio of competencies. Identifying competencies associated with the S-E synthesis process provides a substantive basis for teaching, ideally marrying an understanding of the architecture of S-E synthesis with the tools and habits of mind that support its application. In the framework, these competencies are categorized into four competency domains described below (Fig. 3).

Congruent with Klieme et al. (2008), we use "competency" to encompass the interrelated skills, dispositions, practices, and habits of mind that shape how S-E synthesis work is conducted. These competencies are woven throughout the effort, informing the process and enabling progress toward the desired outcomes. The competency domains define the needed collective capabilities of the team working on S-E synthesis, rather than those of one individual. However, some familiarity with all of the competencies may be fundamental for all who engage in S-E problem-solving. These domains are not exhaustive nor are they mutually exclusive. In addition, their relative importance will vary from one project to the next.

\section{Competency domain \#1: systems thinking}

"Systems thinking" refers to the capacity of an individual or team to recognize and analyze a problem as emerging from an underlying system of dynamic and interdependent forces. By 
"system" we mean "... a set of things - people, cells, molecules, or whatever - interconnected in such a way that they produce their own behavior over time" (Meadows 2008). An important feature of a system is that though it may be affected by outside forces, its response to those forces is determined by the structure of the system. Hence, by understanding the structure of the system, we can understand and anticipate its behavior. By emphasizing systems thinking throughout an S-E synthesis effort, the team keeps the big picture in mind and continually evaluates the boundaries of potential factors to consider. In addition, systems thinking methods are often instrumental in building a common understanding of the problem across stakeholders and disciplinary experts (Gray et al. 2015).

Systems thinking can employ a wide range of methodologies for describing and analyzing the systems that underlie a given S-E problem. These methodologies range from purely qualitative approaches to highly sophisticated computer modeling. Practitioners might employ combinations of approaches such as soft systems analysis (Checkland and Poulter 2007), system dynamics (Morecroft 2015), network analysis (Caldarelli 2013), fuzzy cognitive mapping (Gray et al. 2015), and others. Whatever approach is used, the systems thinking competency domain can be organized into three sub-categories related to 1) describing system structure, 2) relating system structure to emergent behavior, and 3) simulating alternative futures.

First, in order to employ systems thinking, practitioners and students must be able to see beyond simple cause-effect explanations to conceptualize a given S-E problem in terms of the underlying system out of which that problem emerges. Second, simply describing a system is not sufficient for progress toward sustainable solutions. The structure of the system must be explored in order to generate hypotheses about how the system might create and sustain the problem of interest. This requires familiarity and awareness of the role of nonlinearities, feedback, and delays. Finally, simulation methods are often employed to test hypotheses about the extent to which system models can account for current system behaviors, as well as to explore short-term and long-term consequences of options for impacting future system behaviors.

In Nyaki et al. (2014), participatory systems modeling was used with local stakeholders and national-level policymakers to identify the dynamics driving an illegal bushmeat market in Tanzania. The participatory modeling effort revealed significant disconnects between the assumptions of policymakers and the dynamics that actually influence the actions of local actors in the bushmeat market. In addition, the modeling effort demonstrated that these dynamics vary from one village to the next. This variation, along with the misplaced assumptions, had rendered ineffective the top-down policies used up to that time. By adapting those policies to address these issues, more sustainable corrective policies were possible.

\section{Competency domain \#2: integrative research}

S-E synthesis draws upon a wide array of research methodologies, data sources, and theoretical frameworks to study S-E systems (www.sesync.org). Given the interdisciplinary nature of S-E problems, such research requires the integration of disparate and heterogeneous datasets from multiple disciplines and sources, including both qualitative and quantitative data. Thus, practitioners and students should learn a suite of "integrative research" competencies that will prepare them for interdisciplinary, data-intensive research.

These "integrative research" competencies can be organized into two sub-categories: 1) interdisciplinary research practice and design and 2) data analysis and synthesis. Interdisciplinary research practice and design competencies help student learn how to find, read, and synthesize relevant literature (e.g., Wagner 2014); locate and manage both quantitative and qualitative data; and conduct research in an ethical manner (e.g., National Academy of Sciences 2017). Concomitantly, the design of S-E synthesis research projects often requires codeveloping research questions that involve navigating across epistemological and methodological traditions of various disciplines. The second sub-category, data analysis and synthesis, encompasses a constellation of data science skills necessary for working with disparate sources of data and dealing with inherent challenges such as scale mismatches, data availability, and differing standards of evidence. Such competencies include computational skills for data distillation or integration (including visualization), and quantitative and qualitative data analysis.

Integrative research is essential to S-E synthesis work, including formulating data-based hypotheses, generating and evaluating simulations, and conducting risk analysis. Oftentimes, abilities to logically critique natural resource management policies or legal regulations are ultimately dependent on proficient integrative research competencies. For example, in order to reform national policy and institute legally enforced regulations about freshwater pollution, the government of New Zealand drew upon regional research that compared two approaches for establishing catchment loads for diffuse nutrient pollution. One approach was based on a river's "in-stream" nutrient concentration, while the other was based on computer-based predictive modeling (Duncan 2017). A suite of data science skills was necessary to fully understand and cogently interpret the findings of each research approach. Thus integrative research competencies underpinned the ability to compare strengths and weaknesses of each approach, to evaluate implications for compliance and enforcement mechanisms, and ultimately, to critique or propose policy responsive to the complexities involved in measuring and regulating diffuse water pollution. 


\section{Competency domain \#3: boundary crossing}

S-E problem-solving typically requires crossing a wide variety of boundaries between academic disciplines, civil and governmental sectors, and organizations and institutions, as well as research methodologies, epistemological traditions, and even ontological paradigms (Spelt et al. 2009). Thus, students aspiring to become S-E problem-solvers need to develop a particularly sophisticated orientation to boundary crossing (Clark et al. 2011; Reich and Reich 2006).

This domain includes at least two broad categories: 1) skills for facilitating inter- or transdisciplinary collaboration and 2) professional habits of mind conducive to boundary crossing. First, S-E synthesis work often requires collaborative work in cross-disciplinary teams. This brings a unique set of research challenges related to negotiating boundaries between team members and achieving the kind of knowledge integration paramount to S-E synthesis. There is a growing emphasis on developing and promoting effective methods and tools that can facilitate successful collaborative research, particularly for transdisciplinary teams addressing S-E problems (Bammer 2013; Bammer 2017).

S-E synthesis work also requires that differences in perspective are proactively sought and embraced as an opportunity for deeper understanding. Active listening, empathetic patience, and mutual respect may generate novel and innovative ideas that might never have emerged from a single disciplinary perspective. A decidedly solution-driven pragmatism is necessary for practicing these skills in the presence of the inevitable challenges posed by interdisciplinary work. Furthermore, boundary crossing requires a high tolerance for uncertainty, ambiguity, and contradiction.

The importance of the boundary crossing domain can be aptly illustrated by a case study about Minnesota's wolf hunt (Wallace et al. 2014). Hunter and trappers, indigenous groups, farmers and ranchers, and wildlife advocates are among the stakeholder groups impacted by wolf hunting regulations. Because of the wide range of human values associated with wolves, perspectives within and between various stakeholder groups can be highly diverse and sometimes sharply contradictory. Yet, input from multiple stakeholder groups is paramount to the development of pragmatic solutions and workable regulations. Though the design of Minnesota's wolf management plan was based on a "wealth of biological, sociological, cultural, and economic data, reports, and experiences" (Minnesota Department of Natural Resources 2001), its implementation fueled controversy and resulted in extensive court battles. Without sophisticated boundary crossing competencies, it would be difficult to make defensible recommendations about statewide wolf management regulations or to appreciate the complexity of myriad factors that make consensus about wolf hunting regulations so vexingly difficult to achieve.

\section{Competency domain \#4: sociocultural awareness}

Because every S-E system includes social components, dimensions of human societies such as cultural, political, economic, philosophical, historical, and religious influences must be considered. Hence, robust practice of S-E synthesis requires a deep understanding of those influences (Martusewicz et al. 2011). These sociocultural factors involve more than the context within which an S-E problem occurs: They are in fact key elements of the S-E system itself. Their role in that system must be recognized and understood in order to achieve the desired outcomes of S-E synthesis.

The sociocultural competency domain can be organized into three related sub-categories: 1) sociocultural selfawareness, 2) sociocultural contextual awareness, and 3) recognition of the ethical dimensions of decision-making in differing social contexts. First, students need to develop selfawareness of their own identities, cultural beliefs, and viewpoints, as well as awareness and respect for those of others. Failing to do so can lead to a disregard for social values and practices different than one's own, which in turn can result in supposed "solutions" that ignore or devalue critical stakeholders. Achieving sociocultural self-awareness requires frequent self-reflection, tolerance for ambiguity in the presence of values or practices that are outside of experience, and an expansive capacity for empathy - the ability to understand the perspective of others. Second, sociocultural contextual awareness requires knowledge of how social, cultural, political, and economic structures shape the organization and dynamics of S-E systems and necessitates an ability to recognize current and historical inequities in power relationships. Third, understanding the ethical dimensions of S-E decision-making requires that one recognize the value-laden character of risk assessment, along with the invariably unequal distribution of benefits and burdens that are a fundamental feature of many SE problems.

The sociocultural competency domain interacts in profound ways with other competency domains and throughout S-E synthesis problems. Such competence can enable one to recognize the cultural and ideological assumptions encoded in language and to understand why valuations of what constitutes legitimate evidence can differ significantly among stakeholders. Conversely, a lack of such competencies can lead to exclusion of marginalized stakeholders or inequitable decision-making due to projecting one's own values on others or failing to recognize the full impacts of tradeoffs associated with different courses of action.

Though critical to the success of any S-E problem-solving effort, sociocultural awareness is often at risk of being overlooked or ignored. For example, when Bali's traditional Subak rice paddy irrigation system was replaced by technoscientific agricultural practices of the Green Revolution in the 1960s and 1970s, disastrous crop failures ensued. Though 
initially dismissed by scientific experts, the traditional water management system rooted in social, cultural, and religious practices was eventually recognized as highly effective at determining optimal planting and irrigation schedules and thus maximizing rice yields (Lansing 1987; Wei et al. 2014).

\section{Final reflections: using the proposed framework to guide pedagogy}

In a world where environmental issues are increasingly more confounding, complex, and urgent, preparing students to address S-E problems through transdisciplinary research is increasingly important. Yet, given the broad scope of disciplines, perspectives, skills, methods, and knowledge involved in this enterprise, discussions about what students should learn and how to prepare them to become S-E problem-solvers have yielded relatively little clarity. The educational framework proposed here aims to provide better clarity by articulating the desired outcomes of S-E problem-solving efforts, the process by which a transdisciplinary team can achieve these outcomes, the competencies required, and how these elements are woven together to maximize chances of success. Our purpose in developing this holistic framework is to provide guidance to educators in considering what students should learn regarding S-E problem-solving and in developing associated learning goals. The need for such an integrative framework became apparent to us during our workshop as we discussed best practices in teaching about socioenvironmental synthesis: we realized that a common struggle we all had in designing teaching case studies was reconciling a wide range of both content-based, skills-related, and affective learning goals with the learning activities and assessments we were designing for our cases. This framework helps align these elements of pedagogical design by making visible the connections between the various types of learning goals commonly highlighted in environmental and sustainability courses and embedding them in the context of a problem-solving process. This provides an important starting point for designing the activities and assessments that students will engage in to achieve the desired learning outcomes.

Beyond its role in identifying what students should learn, this framework can also provide guidance on how students can learn to be better S-E problem-solvers. By situating competencies in relation to an overarching S-E synthesis process, the framework highlights the importance of exposing students to these competencies in ways that showcase their interdependencies and their roles in S-E problem-solving. We have argued that teaching students a broad range of disciplinary content and skills and assuming students will come to recognize the interdisciplinary connections on their own will not suffice
(Clark and Wallace 2015). Rather, those skills must be deeply embedded in a process of inquiry practiced in a context-rich way so that students can begin to see how all the pieces "fit together" into a whole way of thinking. Because our framework emphasizes the integration of content and process, it provides a unique and complimentary perspective to many other valuable frameworks for sustainability education (Wiek et al. 2011; Lozano et al. 2017; Sterling et al. 2017, and Evans 2019).

As highlighted in articles by Lozano et al. (2017) and Shephard et al. (2019), there is an important need in sustainability education to move beyond the defining of sustainability competencies toward connecting such competencies with pedagogical approaches. Lozano et al. (2017) have developed a framework that maps various pedagogical approaches to a set of commonly defined sustainability competencies to highlight areas of overlap. One notable pedagogical approach that addresses eleven of the twelve competencies listed in their framework is the use of case study methods of teaching (Herreid 1994). Our own experiences match the spirit of this analysis, and we believe that the case study approach is a strong pedagogical approach for teaching students the competencies necessary for S-E problem-solving (Wei et al. 2015, Wei et al. 2018). A deeper analysis of this and other promising pedagogies (e.g., Simon et al. 2013) is beyond the scope of this paper but merits strong attention. Knowing that different approaches leverage different strengths, we remain hopeful that such a comparative analysis will be tackled by scholars in the near future.

Another insight reflected in the framework is that the developmental process novices must undergo to achieve proficiency in S-E research and problem-solving is extensive. This cannot be achieved within the span of a single lesson or course but rather should be targeted as a long-term learning outcome of an intentionally designed curriculum. In this regard, the framework can serve as an evaluative lens that provides benchmarks for examining how pieces of a given curriculum fit within a whole programmatic effort to develop in students the kinds of thinking we describe.

The framework presented here emphasizes the importance of a holistic, integrative view of what students should learn by describing key competencies in the context of an S-E problem-solving process. The question of how students should learn these competencies is still an area that needs further attention, and we join others in calling for more educational research on this topic (Lozano et al. 2017, Sterling et al. 2017). Our hope is that this framework and the pedagogical conversations it stimulates will contribute to the ultimate goal of increasing the effectiveness of curricular materials and instructional experiences designed to prepare students for the vital work of tackling complex socio-environmental problems. 
Open Access This article is licensed under a Creative Commons Attribution 4.0 International License, which permits use, sharing, adaptation, distribution and reproduction in any medium or format, as long as you give appropriate credit to the original author(s) and the source, provide a link to the Creative Commons licence, and indicate if changes were made. The images or other third party material in this article are included in the article's Creative Commons licence, unless indicated otherwise in a credit line to the material. If material is not included in the article's Creative Commons licence and your intended use is not permitted by statutory regulation or exceeds the permitted use, you will need to obtain permission directly from the copyright holder. To view a copy of this licence, visit http://creativecommons.org/licenses/by/4.0/.

\section{References}

American Association for the Advancement of Science (2011) Vision and change in undergraduate biology education: a call to action. http:// visionandchange.org/finalreport. Accessed 26 April 2018

American Association of Physics Teachers (2014) AAPT recommendations for the undergraduate physics laboratory curriculum. https:// www.aapt.org/Resources/upload/LabGuidlinesDocument EBendorsed nov10.pdf. Accessed 26 April 2018

Bammer G (2013) Disciplining interdisciplinarity: integration and implementation sciences for researching complex real-world problems. ANU Press, Canberra

Bammer G (2017) Toolkits for transdisciplinary research. Integration and Implementation Insights: Research resources for understanding and acting on complex real-world problems, https://i2insights.org/2017/ 07/25/toolkits-for-transdisciplinarity/ Accessed 26 April 2018

Burnside WR, Che-Castaldo J, Collins M, Dell-Angelo J (2015) Synthesis: a research approach for studying socio-environmental systems. Talk conducted at the meeting of the Association for Environmental Sciences and Studies, San Diego

Caldarelli G (2013) Scale-free networks: complex webs in nature and technology. Oxford University Press, Oxford

Carpenter S, Armbrust VE, Arzberger PW, Chapin FS III, Elser JJ, Hacket EJ, Ives AR, Kareiva PM, Leibold MA, Lundberg P, Mangel M, Merchant N, Murdoch WW, Palmer MA, Peters DPCC, Pickett STA, Smith KK, Wall DH, Zimmerman AS (2009) Accelerate synthesis in ecology and environmental sciences. BioScience 59(8):699-701. https://doi.org/10.1525/bio.2009.59.8. 11

Checkland P, Poulter J (2007) Learning for action: a short definitive account of soft systems methodology, and its use for practitioners, teachers and students. J. J. Wiley

Clark SG, Wallace RL (2015) Integration and interdisciplinarity: concepts, frameworks, and education. Policy Sci 48:233-255

Clark SG, Steen-Adams MM, Pfirman S, Wallace RL (2011) Professional development of interdisciplinary environmental scholars. J Environ Stud Sci 1(99):99-113. https://doi.org/10.1007/ s13412-011-0018-z

Collins MB, Munoz I, JaJa J (2016) Linking 'toxic outliers' to environmental justice communities. Environ Res Lett 11(1):015004

Duncan R (2017) The challenges of regulating diffuse agricultural pollution to improve water quality: a science policy perspective on approaches to setting enforceable catchment load limits in New Zealand. Case Stud Environ 1(1):1-7. https://doi.org/10.1525/cse. 2017.sc.433549

Eigenbrode S, O'Rourke M, Wulfhorst JD, Althoff DM, Goldberg CS, Merrill K et al (2007) Employing philosophical dialogue in collaborative science. Bioscience 57(1):55-64. https://doi.org/10.1641/ B570109

Evans TL (2019) Competencies and pedagogies for sustainability education: a roadmap for sustainability studies program development in colleges and universities. Sustainability 11(5526). https://doi.org/10. 3390/su11195526

Frisk E, Larson KL (2011) Educating for sustainability: competencies \& practices for transformative action. J Sustain Educ 2(1):1-20 Retsrieved from http://www.jsedimensions.org/wordpress/wpcontent/uploads/2011/03/FriskLarson2011.pdf

Gray SA, Gray S, De Kok JL, Helfgott AER, O’Dwyer B, Jordan R, Nyaki A (2015) Using fuzzy cognitive mapping as a participatory approach to analyze change, preferred states, and perceived resilience of social-ecological systems. Ecol Soc 20(2):11. https://doi. org/10.5751/ES-07396-200211

Herreid CF (1994) Case studies in science-a novel method of science education. J Coll Sci Teach 23(4):221-229

Klieme E, Hartig J, Rauch D (2008) The concept of competence in educational contexts. In: Hartig J, Klieme E, Leutner D (eds) Assessment of competencies in educational contexts. Hogrefe \& Huber Publishers, Boston, pp 3-22

Lansing JS (1987) Balinese 'water temples' and the management of irrigation. Am Anthropol 89:326-341

Liu J, Dietz T, Carpenter SR, Alberti M, Folke C, Moran E, Pell AN, Deadman P, Kratz T, Lubchenco J, Ostom E, Ouyang Z, Provencher W, Redman CL, Schneider SH, Taylor WW (2007) Complexity of coupled human and natural systems. Science 317:1513-1516. https://doi.org/10.1126/science.1144004

Lozano R, Merrill M, Sammalisto K, Ceulemans K, Lozano F (2017) Connecting competences and pedagogical approaches for sustainable development in higher education: a literature review and framework proposal. Sustainability 9(10):1889. https://doi.org/10.3390/ su9101889

Lynch AJJ, Thackway R, Specht A, Beggs PJ, Brisbane S, Burns EL, Byrne M, Capon SJ, Casanova MT, Clarke PA, Davies JM, Dovers S, Dwyer RG, Ens E, Fisher DO, Flanigan M, Garnier E, Guru SM, Kilminster K, Locke J, Mac Nally R, McMahon K, Mitchell PJ, Pierson JC, Rodgers EM, Russell-Smith J, Udy J, Waycott M (2015) Transdisciplinary synthesis for ecosystem science, policy and management: the Australian experience. Sci Total Environ 534:173-184. https://doi.org/10.1016/j.scitotenv.2015.04.100

Martusewicz RA, Edmundson J, Lupinacci J (2011) EcoJustice eduation: toward diverse, democratic, and sustainable communities. Routledge, New York

Marzano RJ (2009) Designing \& teaching learning goals \& objectives. Marzano Research, Bloomington

Meadows DH (2008) In: Wright D (ed) Thinking in systems: a primer. Chelsea green publishing, White River junction

Minnesota Department of Natural Resources (2001) Minnesota Wolf Management Plan. http://files.dnr.state.mn.us/natural_resources/ animals/mammals/wolves/wolfplan.pdf. Accessed April 26, 2018

Mobjörk M (2010) Consulting versus participatory transdisciplinarity: a refined classification of transdisciplinary research. Futures. 42(8): 866-873. https://doi.org/10.1016/j.futures.2010.03.003

Morecroft JDW (2015) Strategic modeling and business dynamics: a feedback systems approach, 2ed. John J. Wiley

National Academies of Sciences, Engineering, and Medicine (2017) Fostering integrity in research. The National Academies Press, Washington. https://doi.org/10.17226/21896

National Academy of Sciences, National Academy of Engineering, and Institute of Medicine (2005) Facilitating interdisciplinary research. The National Academies Press, Washington. https://doi.org/10. $17226 / 11153$

Nyaki A, Gray SA, Lepczyk CA, Skibins JC, Rentsch D (2014) Localscale dynamics and local drivers of bushmeat trade. Conserv Biol 28(5):1403-1414. https://doi.org/10.1111/cobi.12316

Ostrom E (2009) Understanding institutional diversity. Princeton University Press, Princeton 
Palmer MA (2012) Socioenvironmental sustainability and actionable science. BioScience 62(1):5-6. https://doi.org/10.1525/bio.2012.62.1. 2

Palmer M (2017) [SESYNC]. Part 3: Approaches and methods to integrate diverse socio-environmental data [Video File]. Retrieved from https://www.youtube.com/watch?time continue $=171 \& \mathrm{v}=$ Fwm0xPTqJSE. Accessed 3 Apr 2020

Palmer MA, Kramer JG, Boyd J, Hawthorne D (2016) Practices for facilitating interdisciplinary synthetic research: the National SocioEnvironmental Synthesis Center (SESYNC). Curr Opin Envir Sustain 19:111-122. https://doi.org/10.1016/j.cosust.2016.01.002

Pennington D, Bammer G, Danielson A, Gosselin D, Gouvea J, Habron G, Hawthorne D, Parnell R, Thompson K, Vincent S, Wei C (2016) The EMBeRS project: employing model-based reasoning in socioenvironmental synthesis. J Environ Stud Sci 6(2):278-286. https:// doi.org/10.1007/s13412-015-0335-8

Phillips BF, Melville-Smith R, Caputi N (2007) The western rock lobster fishery in Western Australia. In Fisheries Management: Progress Towards Sustainability, edited by McClanahan and Castilla, J.C. Blackwell Publishing Ltd.

Reich SM, Reich JA (2006) Cultural competence in interdisciplinary collaborations: a method for respecting diversity in research partnerships. Am J Community Psychol 38(1-2):51-62. https://doi.org/10. 1007/s10464-006-9064-1

Segalas J, Ferrer-Balas D, Svanstrom M, Lundqvist U, Mulder KF (2009) What has to be learnt for sustainability? A comparison of bachelor engineering education competencies at three European universities. Sustain Sci 4(1):17-27. https://doi.org/10.1007/s11625-009-0068-2

Shephard K, Rieckmann M, Barth M (2019) Seeking sustainability competence and capability in the ESD and HESD literature: an international philosophical hermeneutic analysis. Environ Educ Res 25(4): 532-547

Simon GL, Wee BS, Chin A, Tindle AD, Guth D, Mason H (2013) Synthesis for the interdisciplinary environmental sciences: integrating systems approaches and service learning. J Coll Sci Teach 42(5): 42-49

Spelt EJH, Biemans JA, Tobi H, Luning PA, Mulder M (2009) Teaching and learning in interdisciplinary higher education: a systematic review. Educ Psychol Rev 21(4):365-378. https://doi.org/10.1007/ s10648-009-9113-Z
Sterling S, Glasser H, Rieckmann M, Warwick P (2017) "More than scaling up": a critical and practical inquiry into operationalizing sustainability competencies. In: Corcoran PB, Weakland JP, Wals AEJ (eds) Envisioning futures for environmental and sustainability education. Wageningen Academic Publishers, Wageningen, pp $153-168$

Sterman JD (2000) Business dynamics: systems thinking and modeling for a complex world. McGraw Hill

Turner BL II, Esler KJ, Bridgewater P, Tewksbury J, Sitas N, Abrahams B et al (2016) Socio-environmental systems (SES) research: what have we learned and how can we use this information in future research programs. Curr Opin Envir Sustain 19:160-168. https:// doi.org/10.1016/j.cosust.2016.04.001

Vincent S, Focht W (2010) In search of common ground: exploring identity and the possibility of core competencies for interdisciplinary environmental programs. Environ Pract 12(1):76-86. https://doi. org/10.1017/S1466046609990433

Vincent S, Focht W (2011) Interdisciplinary environmental education: elements of field identity and curriculum design. J Environ Stud Sci 1:14-35. https://doi.org/10.1007/s13412-011-0007-2

Wagner G (2014) Research-based learning. In: Quave CL (ed) Innovative strategies for teaching in the plant sciences. Springer Press, New York, pp 61-82

Wallace A, Shume T, Garrett S, Lindaas S (2014) Minnesota wolf hunt. National Socio-Environmental Synthesis Center. https://www. sesync.org/minnesota-wolf-hunt-2013-9. Accessed April 26, 2018

Wei CA, Burnside WR, Che-Castaldo JP (2014) The blind spot in the green revolution: temples, terraces, and rice farmers of Bali. National Socio-Environmental Synthesis Center. https://www. sesync.org/the-blind-spot-in-the-green-revolution-case-study-14. Accessed April 26, 2018

Wei CA, Burnside WR, Che-Castaldo JP (2015) Teaching socioenvironmental synthesis with the case studies approach. J Environ Stud Sci 5(1):42-49. https://doi.org/10.1007/s13412-014-0204-x

Wiek A, Withycombe L, Redman C (2011) Key competencies in sustainability: a reference framework for academic program development. Sustain Sci 6:203-218. https://doi.org/10.1007/s11625-011-0132-6

Wei CA, Brown M, Wagner M (2018) Pursuing the promise of case studies for sustainability and environmental education: converging initiatives. Case Stud Env 2(1):1-8. https://doi.org/10.1525/cse. 2018.001065 